\title{
CHARACTERISTICS OF WATER HYDRAULIC SERVO SYSTEM
}

\author{
Naruhiko OOKUBO, Shigeki MIURA, Shigeru IKEO, \\ Yasuo SAKURAI and Koji TAKAHASHI \\ Department of Mechanical Engineering \\ Faculty of Science and Technology \\ Sophia University \\ 7-1, Kioicho, Chiyoda-ku, Tokyo, 102-8554 Japan
}

\begin{abstract}
Recently, the demand for using pure tap water as a pressure medium in hydraulic applications has increased due to its availability, Its low cost and its high safety levels against pollution and fire hazard. This is a report on the result examining the Influence that was exerted by the characteristics of the water on the performance of the water hydraulic servo system by experiments and simulations also comparing with the conventional oil hydraulic servo system. The comparison is based on the position control of a cylinder using PI controller by changing the temperature of the pressure medium.
\end{abstract}

\section{KEY WORDS}

Water hydraulic, Temperature, Frequency response, Servo cylinder, Cavitation

\section{NOMENCLATURE}

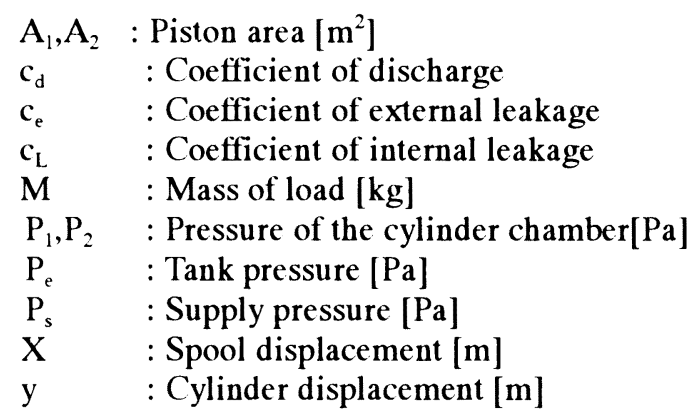

\section{INTRODUCTION}

In the early years, water was the most applied fluid as a pressure medium for fluid power applications. But in the early $20^{\text {th }}$ century, a pump directly connected to a prime mover using oil as a pressure medium came out. Consequently, from the 1930 's the oil became the main pressure medium of hydraulic applications.

By altering the medium from water to oil, solved the problems like lubrications that arised during the process to improve the size of the machines and the performance. Oil as a pressure medium contributed immensely to the advance of fluid power technology and it's prosperity. 


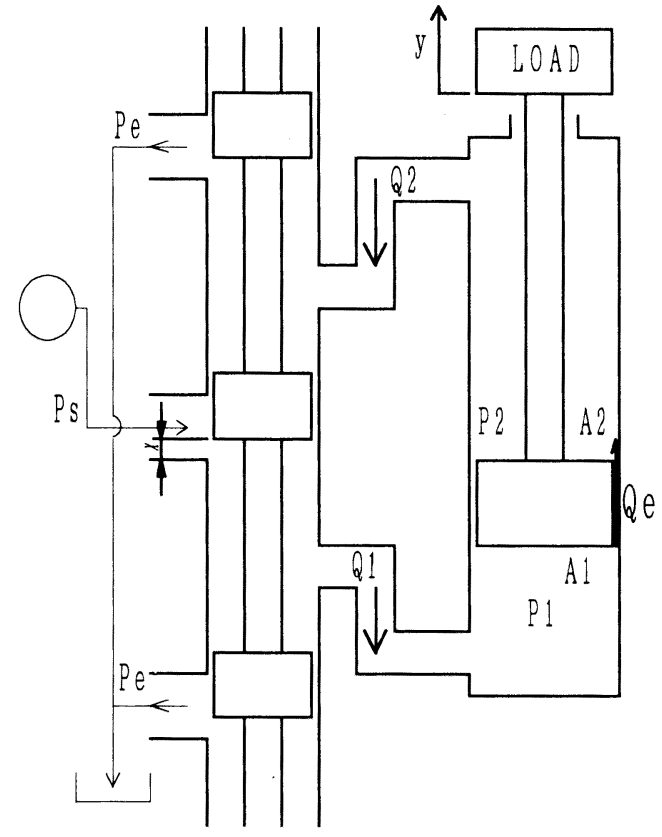

Fig.1 Servo system

In the 1940's water glycol and in the 1950's W/O emulsion came into use to satisfy the prevention against fire hazards.

For the performance, reliability and durability of the hydraulic systems, the management to keep the quality of the fluid in use is a very important factor. Filtration to remove solid particles and a standard for measuring the contamination of the fluid is inevitable. But in contrast, keeping the quality of the fluid is an annoying job for an user of the hydraulic system.

Water is the most available fluid on earth. And also has no problems against the waste, the environment and it's characteristics are known widely. From the present point of view, oil has an advantage against water in the aspect of lubrication but the recent technology of materials, designs and tribology has brought the possibility of using water as a pressure medium again[1] [3].

The aim of this research is to examine the difference between oil and water as a pressure medium and to find out the problems of using water. The effect of the change in the temperature of pressure medium on the position control of a cylinder will be investigated through simulation and experiments. Furthermore the possibility of cavitation in the water hydraulic cylinder will be investigated experimentally and compared with the cavitation in the oil hydraulic cylinder[4].

\section{MATHEMATICAL MODEL}

The schematic diagram of the servo system is shown in figure 1.
Under the following assumptions, the mathematical model of the servo system was derived.

(1) There are no external leakage from the servo valve and the cylinder.

(2) There are no overlap between the valve body and the spool.

(3) Spool displacement is linear to the input voltage applied to the servo amplifier.

(4) The density and the viscosity of the medium are dependent on the temperature, but is assumed to be constant during the movement of the plant.

(5) The supply pressure from the power unit is constant.

(6) The internal leakage is approximated by the by the flow equation of a circular opening.

The spool displacement $\mathrm{X}$ and the cylinder displacement $\mathrm{y}$ are both positive upwards. When the bulk modulus of the fluid is denoted by $\mathrm{K}$, the equation of continuity at the cylinder chamber is expressed as follows.

$$
\begin{aligned}
& \frac{V_{1} d P_{1}}{K d t}=Q_{1}-A_{1} \frac{d y}{d t}-c_{L}\left(P_{1}-P_{2}\right) \\
& \frac{V_{2} d P_{2}}{K d t}=-Q_{2}+A_{2} \frac{d y}{d t}+c_{L}\left(P_{1}-P_{2}\right)-c_{e}\left(P_{2}\right)
\end{aligned}
$$

where $c_{L}$ is the coefficient of internal leakage and $c_{e}$ the external leakage.

The flows through the spool valve $Q_{1}$ and $Q_{2}$ are expressed as follows:

when $\mathrm{X} \geqq 0$

$$
\begin{aligned}
& Q_{1}=c_{d} w \sqrt{\frac{2}{\rho}} X \operatorname{sign}\left(P_{s}-P_{1}\right) \sqrt{\left|P_{s}-P_{1}\right|} \\
& Q_{2}=c_{d} w \sqrt{\frac{2}{\rho}} X \operatorname{sign}\left(P_{2}-P_{e}\right) \sqrt{\left|P_{s}-P_{e}\right|}
\end{aligned}
$$

when $\mathrm{X}<0$

$$
\begin{aligned}
& Q_{1}=c_{d} w \sqrt{\frac{2}{\rho}} X \operatorname{sign}\left(P_{1}-P_{c}\right) \sqrt{\left|P_{1}-P_{c}\right|} \\
& Q_{2}=c_{d} w \sqrt{\frac{2}{\rho}} X \operatorname{sign}\left(P_{s}-P_{2}\right) \sqrt{\left|P_{s}-P_{2}\right|}
\end{aligned}
$$

where $c_{d}$ is the coefficient of discharge, $w$ the width of the port and $\rho$ the density of the pressure medium.

In this research, the cylinder is set up horizontally, so the equation of motion can be described as,

$$
M \frac{d^{2} y}{d t^{2}}=A_{1} P_{1}-A_{2} P_{2}
$$

\section{EXPERIMENT AND SIMULATION}

The experimetal rig used in this research is shown in figure 2. The plant consists of 5 components which are the water hydraulic power unit (rated pressure $14 \mathrm{Mpa}$ ), the servo valve (rated flow $10 \mathrm{~L} / \mathrm{min}$ at pressure drop $7 \mathrm{Mpa}$ ), the single rod cylinder (full stroke $0.05 \mathrm{~m}$ ), the 


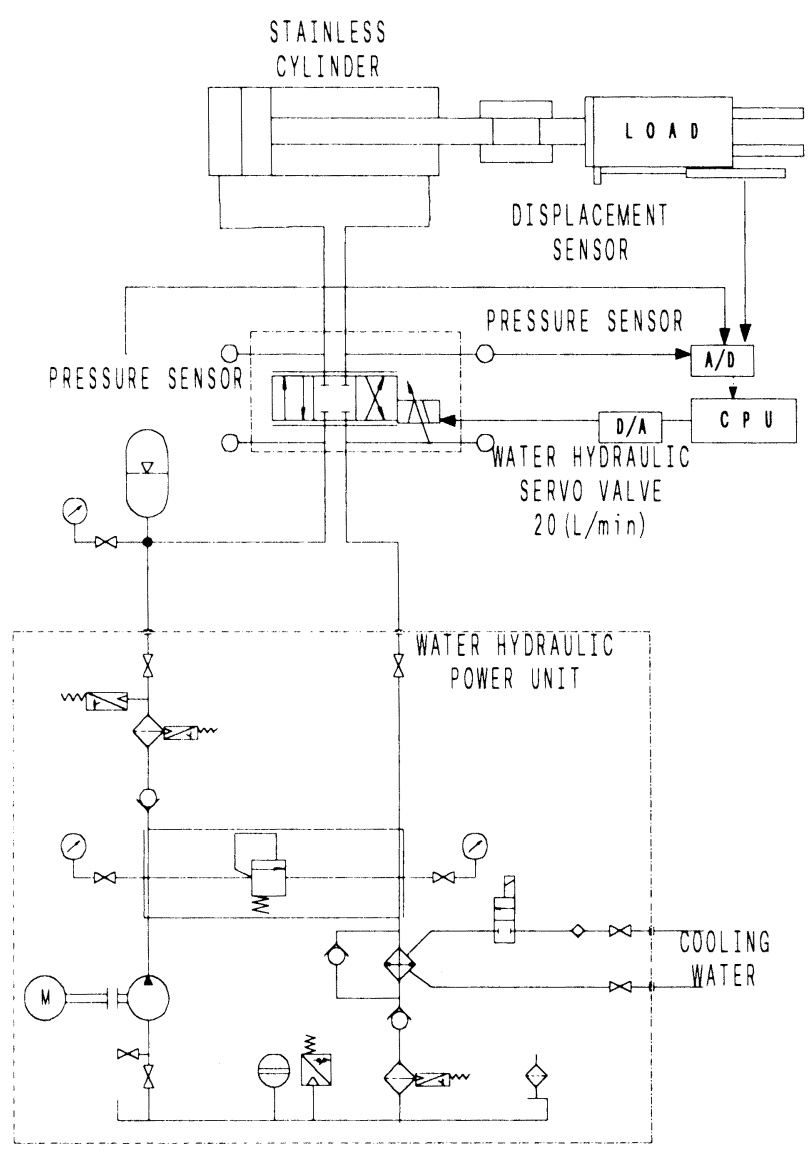

Fig. 2 Experimental rig

inertial load $(40 \mathrm{~kg})$ and the control devices. The cylinder is set up horizontally and the load on the rail is attached at the end of the rod. Also the pipes used in this rig are all made of stainless steel.

In this research, the frequency response of the cylinder position was experimented. In order to reduce the drift of the piston due to the asymmetry, PI-controller is used in the experiment. In the frequency response, the input voltage to the servo amplifier is taken as input signal and the displacement of the cylinder as output signal. Both signals are normalized by the signals at the frequency of $0.05 \mathrm{~Hz}$ (amplitude of cylinder displacement $0.10 \mathrm{~m}$ ). In order to study the effects of fluid temperature on the characteristics of water hydraulic servo system, the frequency response was examined at temperatures of $10^{\circ} \mathrm{C}, 20^{\circ} \mathrm{C}, 30^{\circ} \mathrm{C}, 40^{\circ} \mathrm{C}, 45^{\circ} \mathrm{C}$ by using a cooling device. By simulation, the difference between the position control using oil and water as a pressure medium and the effect of the oil temperature to the position control was investigated.

\section{RESULT}

Figure 3 shows the experimentally obtained frequency
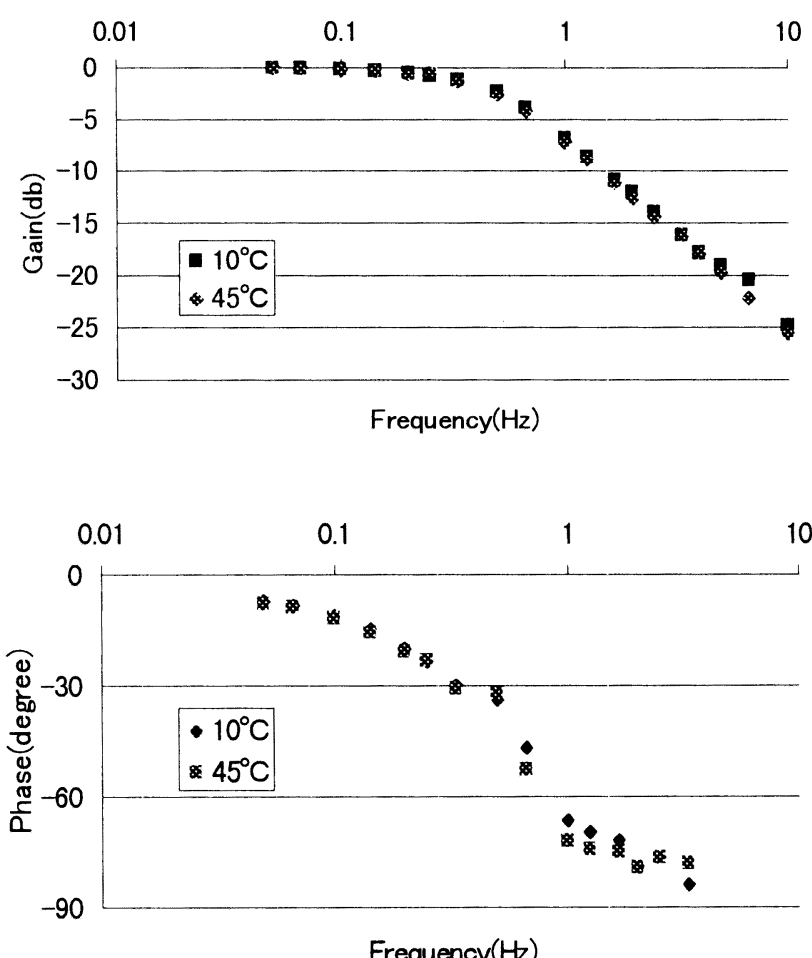

Fig.3 Frequency response (experiment, water)
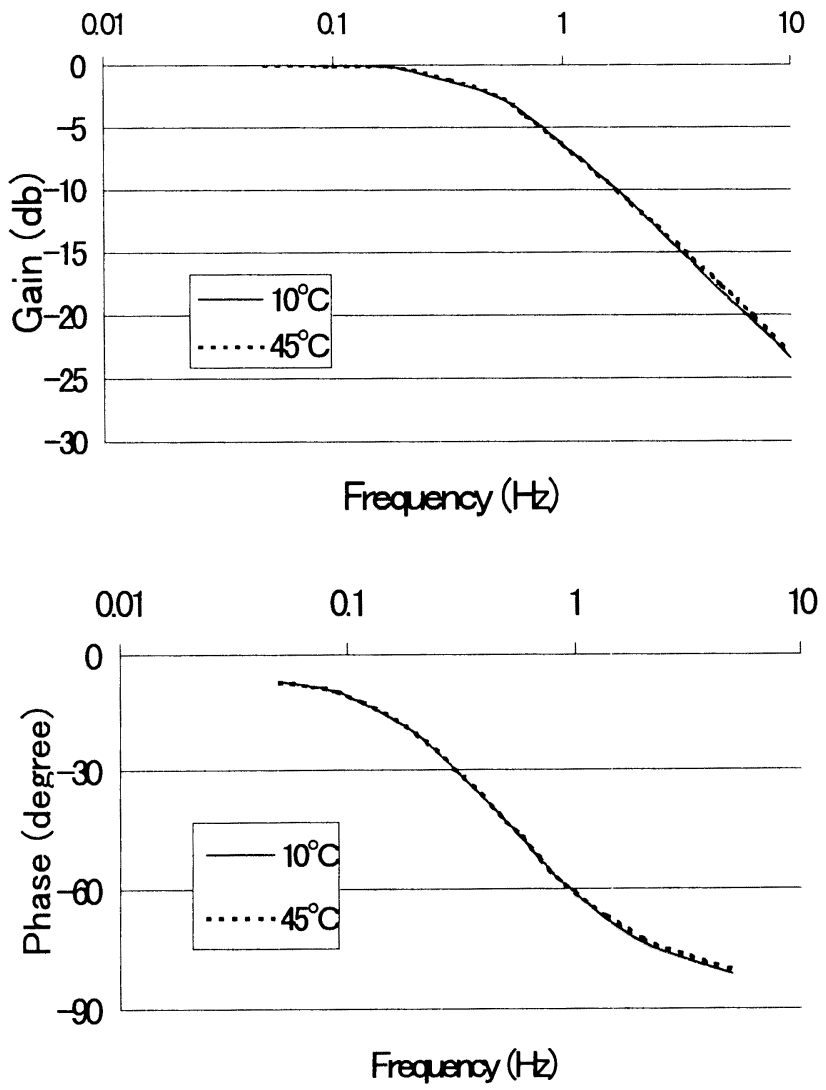

Fig4 Frequenoy response (simulation, weter) 

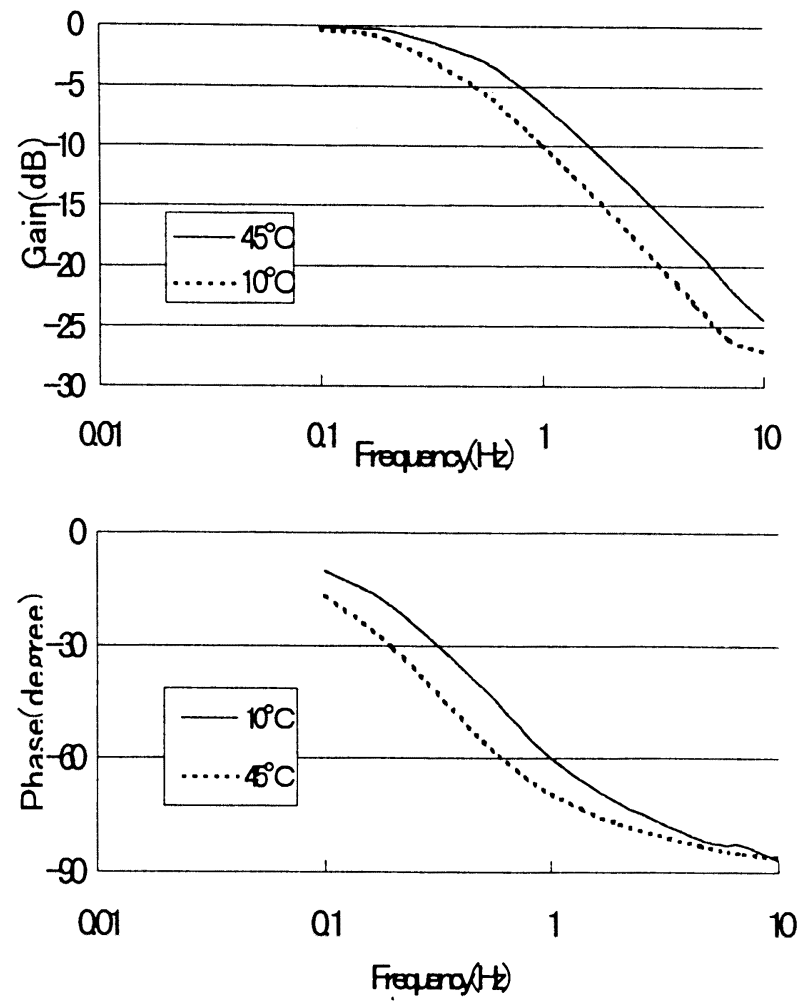

Fig.5 Frequency response of open loop system
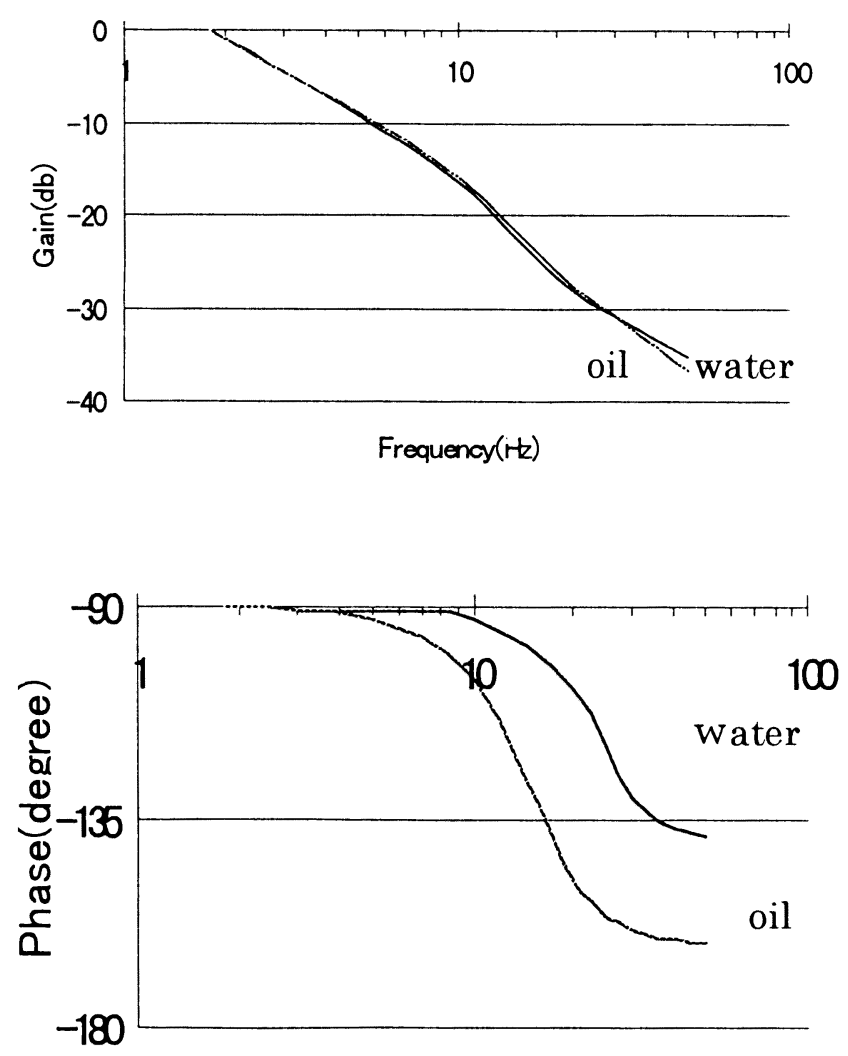

Frequanalte)

Fig.6 Frequency response of open loop system response of the servo system when the water temperature is at $10^{\circ} \mathrm{C}$ and $45^{\circ} \mathrm{C}$. There is no difference in the change of the temperature, but some disorder can be seen from the phase. The reason is thought to be the problem of the accuracy of the displacement sensor at the high frequency level when the gain is low.

It can be also seen from the simulated result in figure 4 that the water temperature does not effect the position control of the cylinder. But the difference between the gain from the experimented result and the simulated result can be reasoned as the influence of the simplification of the model. Figure 4 and 5 shows the frequency response of the servo system obtained by simulation when oil and water is used respectively. From figure 5 , it can be seen that the response of the system declines as the oil temperature gets lower.

Figures 3 to 5 indicate the characteristics of the closed loop servo system. The characteristics includes not only the characteristics of the fluid power drive system, but also the PI-controller. To make the difference between the water hydraulic system and oil hydraulic system clear, the frequency responses of the open loop systems are simulated. The results of simulations are compared in figure 6 . It can be seen from figures 4 to 6 that the

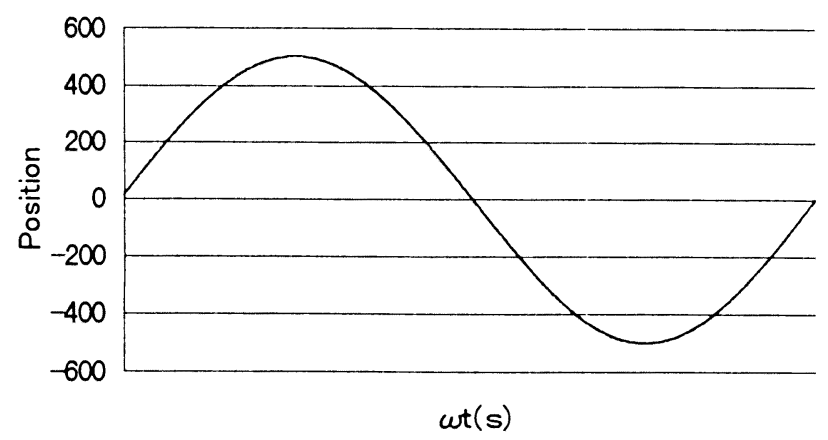

(a) Position

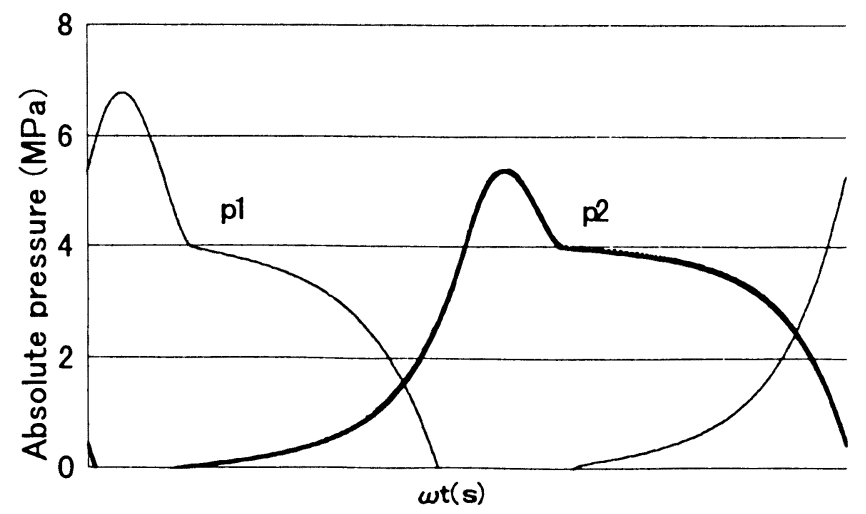

(b) Absolute pressure $(30 \mathrm{~Hz}, 1000 \mathrm{~kg}, 7 \mathrm{Mpa})$

Fig. 7 Pressure in the cylinder 
response of water hydraulic system is better than the oil hydraulic system.

The performance of the system is dependent on the temperature of pressure medium. In the case of oil hydraulic servo system, the kinematic viscosity of oil changes greatly according to it's temperature. The kinematic viscosity changes from $100 \mathrm{~mm}^{2} / \mathrm{s}$ to $18 \mathrm{~mm}^{2} / \mathrm{s}$ when the oil temperature is altered from $10^{\circ} \mathrm{C}$ to $45^{\circ} \mathrm{C}$.

This sudden change in kinematic viscosalso changes the coefficient of discharge largely. The coefficient of discharge is a function of the Reynolds number which can be defined as $\operatorname{Re}=v d / \nu$. The decrease in kinematic viscosity increases the Reynolds number and also increases the coefficient of discharge which means that the volume flow rate of the oil flowing through the valve increases at a same pressure change. Increasing the volume flow rate improves the performance of the gain as well as the phase at it's low frequency area.

Using water does not change the performance of the system for the change in kinematic viscosity to the temperature is so small compared to oil. Numerically, the kinematic viscosity changes from $1.32 \mathrm{~mm}^{2} / \mathrm{s}$ to $0.51 \mathrm{~mm}^{2} / \mathrm{s}$ when the water temperature is altered from $10^{\circ} \mathrm{C}$ to $45^{\circ} \mathrm{C}$. The kinematic viscosity of oil changes about 5 times larger where water only changes about 2.5 times larger when the temperature is set from $10^{\circ} \mathrm{C}$ to $45^{\circ} \mathrm{C}$. Another reason can be thought that the kinematic viscosity of water is smaller than oil in general. The coefficient of discharge increases to 0.77 accompanied by the increase of the Reynolds number up to about 200 . Then, as the Reynolds number increase up to 500, the coefficient of discharge gradually decreases to 0.74 . But the coefficient of discharge does not change where the Reynolds number is above 500. Thus the Reynolds number for water is over 500 , because the kinematic viscosity of water is so small.

Figure 7 shows the simulated result of the pressure inside the cylinder when water is used. It can be seen that the absolute pressure becomes negative at some places. Scince the vapor pressure of water is higher than that of oil, it seems that water hydraulic servo system has more risk of cavitation.

\section{CAVITATION}

In order to investigate the possibility of cavitation in the water hydraulic cylinder, the experimental rig is modified as shown in figure 8 . The transparent cylinder made of acrylic resin is connected with the inertial load and is driven by the stainless cylinder. During the cylinder drive water is fed from small resevoier. The velocity of piston movement can be controlled by the servo valve. The inside of the transparent cylinder is observed when the cylinder is driven at various speed.

Similar experiments using oil instead of water are performed and the possibility of cavitation is examined.

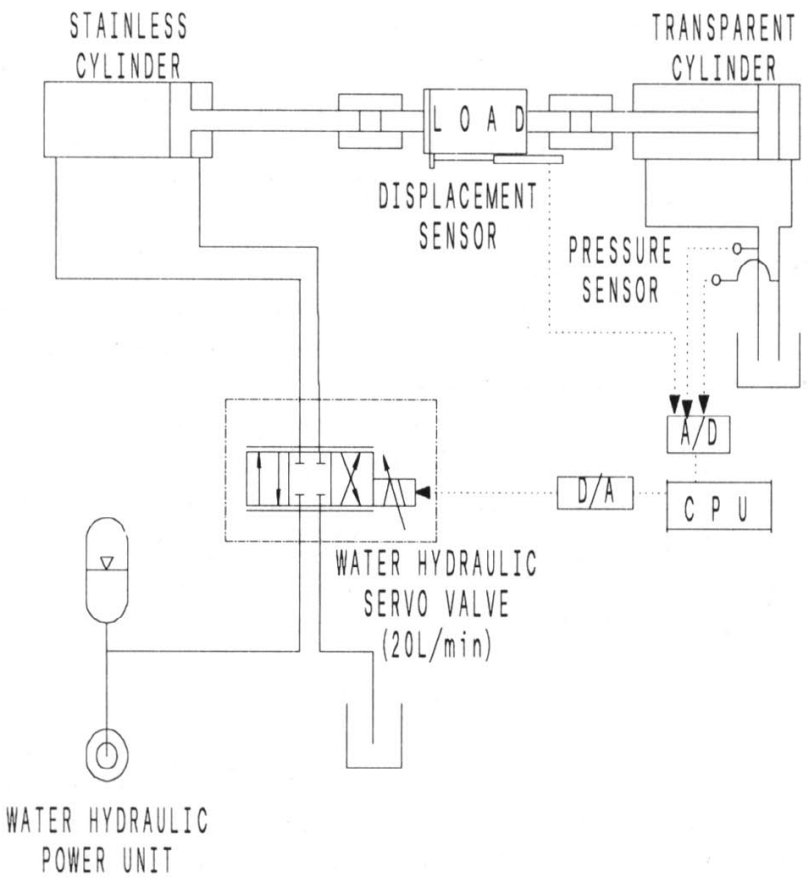

Fig. 8 Experimental rig for cavitation observation

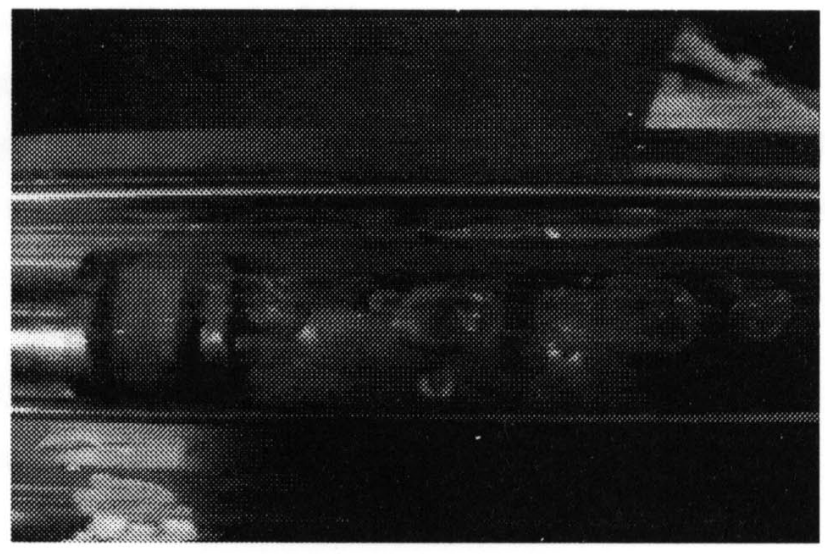

Fig. 9 Cavitation in cylinder chamber (water)

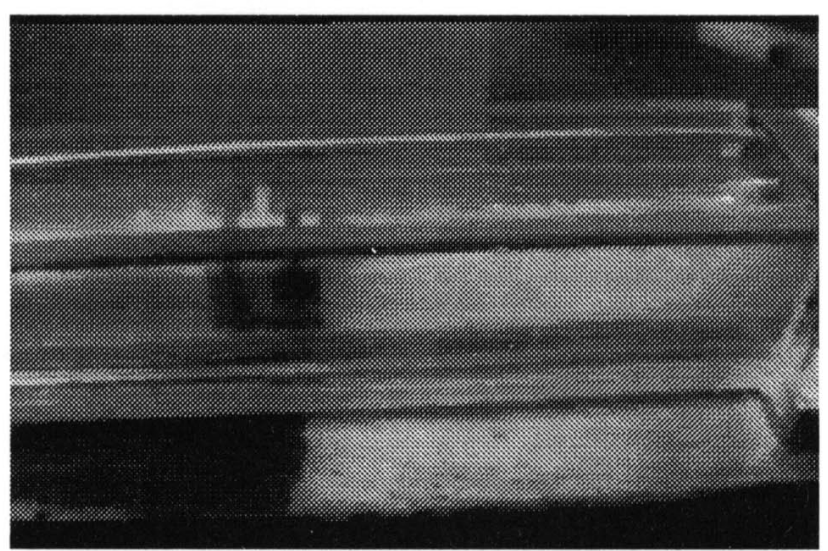

F ig. 10 Cavitation in cylinder chamber (oil) 
Figure 9 shows the cavitation caused by the piston movement using water. Several small cavities suddenly appear in the cylinder when the piston velocity becomes high. After the piston stops, some of cavities are disappeared and some are remained even though the size of cavity is reduced. Figure 10 shows the cavitation when the oil is used. The critical speed of piston for water is $150 \mathrm{~mm} / \mathrm{s}$ and for oil $100 \mathrm{~mm} / \mathrm{s}$. The reason for this curious results is that the solution of air in oil is much more than that in water.

The initial pressure in the cylinder chamber was almost same as the atmospheric pressure in this cavitation observation, the situation in actual water hydraulic cylinder may differ a little. Further experiments are necessary to be able to predict the occurrence of cavitation in water hydraulic cylinder.

\section{CONCLUSION}

In this research, frequency response of a servo system with a cylinder as an actuator was simulated. Further more, the effect of the change in water temperature to theposition control was experimented. From the results, it was found out that the performance of the oil hydraulic servo system declines when the temperature decreases. But the performance of the water hydraulic servo system does not change regardless to the change in temperature occurs in water hydraulic cylinder.

The authors wish to express their appreciation to Dr. S.Miyakawa and the members of water hydraulic division in Ebara Research Co.Ltd. for their helpful advices on our experiments.

\section{REFERENCES}

1. E.Trostmann, Water Hydraulics Control Technology, Marcel Dekker, Inc., 1995.

2. E.Urata, S.Miyakawa and C.Yamashina, Hydrostatic Support of Spool for Water Hydraulic Servovalves, Proc. 4th Scandinavian International Conference on Fluid Power, 1995, 2-2, pp.910-929.

3. Nessie TM, Wasserhydraulik arbeitet mit Klarwasser, o+p, 1994, 38-12, pp45-46.

4. D.McCloy, Cavity Formation in Valve Controlled Hydraulic Cylinders, Proceedings of the Institution of Mechanical Engineers, 1969-1970, Vol.184 Pt.1 No.52, pp.969-977. 